\title{
Towards an Integrative Approach to Spatial Transformation
}

\author{
Addressing Contextual and Spatial Indifference in Design, \\ Urban Planning and International Cooperation: A Case Study \\ from Addis Ababa
}

Sascha Delz

\begin{abstract}
This chapter draws from the author's research on recent urbanisation processes in Ethiopia's capital, Addis Ababa, and its hinterland. It addresses two aspects that are often neglected but crucial when discussing how to adequately address urbanisation along economic development and structural transformation lines: the importance of contextual differences, and the impact of spatial formation. Along these lines, two observations are highlighted: first, that there is an obvious need for new concepts of urbanisation that are driven by, and appropriate for, African contexts; and second, that it is fundamental to reconsider the role of space for economic development and structural change. Addressing these issues, the author argues for a move away from simplistic and abstract models of transition-which have substantially influenced the outcomes of development policies, international development cooperation and spatial practices - and for the exploration of more integrative, contextually informed models of transformation. Using an example of road construction in Ethiopia's capital Addis Ababa, the chapter firstly addresses particular issues related to policies of transition, and secondly, outlines an alternative approach that could address the complex challenges of economic, social and spatial transformation in a more integrative, contextually relevant manner. Suggesting a more open, spatially conscious stance (i.e. dialogic design and planning) and a more collectively conceived planning process (i.e. collective ground), the chapter thus advocates that when dealing with the complex challenges of everyday spaces for urban dwellers, future urban development policies should rather enable a multitude of contextually adequate and integrative proposals than promote a restrained catalogue of universally applied solutions.
\end{abstract}

(C) SASCHA DELZ, 2018 | DOI:10.1163/9789004387942_009

This is an open access chapter distributed under the terms of the prevailing CC-BY-NC License at the time 004387942 of publication. 
"Transition" implies a transformation between known points in time, "transformation" a structural change into something yet unknown. HETTNE, 2009, 30

\section{Introduction}

\subsection{Contextual and Spatial Blind Spots in Urban Development and International Cooperation}

As so many sectors within the so-called global South, urban development, urban planning and urban design have been strongly intertwined with the global North's interventions through colonisation, and, since World War II, through the international frameworks of technical assistance and development cooperation. It is thus of no surprise that within the urban realm most of the concepts and methods for addressing urbanisation processes-in all involved disciplines-have been dominated by approaches developed in and for Western cities (Okpala, 1990; Healey, 2010; Ward, 2010). Furthermore, despite the emerging spatial turn within the academic fields of (mainly) the social sciences and the humanities starting in the 1970s (Low, 2014, 19-21), many development cooperation policies and projects appear to have repeatedly neglected such new perspectives and have thus maintained blind spots for the spatial realm in general, and the related effects on the built environment in particular. Intrinsically linked to the physical world however, urban configurations shaped by both imported concepts and spatially indifferent development policies have determined urban spaces of the everyday lives of urban citizens for better or - too often-worse. Thus, the general failure to genuinely accept locally evolved categories and criteria that could more suitably describe processes on the ground has been one of the key omissions with regard to adequately engaging with the challenges of structural and urban transformation in the respective contexts.

Addressing these issues within the context of African urbanisation, as well as from a perspective of spatial design, urban design and spatial planning, this chapter will briefly introduce the so-called Ring Road project that has been implemented through a collaboration involving Chinese actors and British engineers in Ethiopia's capital Addis Ababa. The Ring Road is one of the subjects of the author's recently finished dissertation, which follows an empirical bottom-up exploration structured along a methodological framework that combines case study research —as defined by Robert K. Yin — with a narrative inquiry as described within the methodology of phronetic planning research 
by Bent Flyvbjerg (Yin, 2003; Flyvbjerg, 2004). ${ }^{1}$ Within this set-up, the chosen bottom-up trajectory has been a key method with regard to how to conduct the overall research: rather than beginning with the related theoretical frameworks of political, spatial and economic perspectives, each case study's starting point was an analysis of its physical manifestation. Following and unveiling the respective underlying processes that influenced these spatial results allowed a more precise introduction of the relevant theoretical, political and historical frameworks along the way. In summary — and as in the words of James Duminy, Nancy Odendaal and Vanessa Watson-applying a case study approach to the issues at hand is seen as a crucial methodology with regard to how to produce 'data and knowledge on African urbanisation, [...] [because it] allows the interweaving of qualitative and quantitative data in order to present nuanced explanations of how planning interventions intersect with everyday practices' (Duminy et al., 2014, 197-198). It is clear that within the limits of this chapter it is impossible to trace the complete process of the applied bottom-up trajectory or recapitulate the entire case study. Rather, the presented argument directly starts with some aspects of the dissertation's conclusion, shows parts of the empirical findings related to the respective case study, and ends with remarks that draw from - and extend — the original research's closing arguments. Reflecting on the results of the author's dissertation, and in accordance with the related introductory statements, the chapter will address following three aspects: a) the necessity of revisiting the underlying mechanisms of established conceptions of development cooperation, urbanisation and spatial planning; b) the importance of highlighting and re-conceptualizing the significance of the built environment and its physical impact on everyday lives; and c) a proposition towards more pluralistic, context-based practices that allow spatial and structural change to be shaped in a more integrative and adequate manner.

\subsection{Thinking in Transitions and Dialectic Thinking}

At the core of the following discussion on why things happen the way they do, and how they could be changed for that matter, lies the crucial distinction between transition and transformation as phrased by Björn Hettne in the introductory quote. The prospect of linear progress has not only substantially formed general discourse on development, it has also enduringly influenced the simultaneously established, official frameworks of development

1 The author's dissertation investigates three different projects of international development cooperation within and around Ethiopia's capital Addis Ababa. Including various global actors (German, Chinese and Dutch), and covering the sectors of housing, road construction and export agriculture, the research critically analyses the interrelation between underlying cooperation approaches, the applied financial models, and the resulting spatial impacts on the ground. 
aid, assistance and cooperation (Martinussen, 1997). Indeed, looking at the origins of development thinking as framed by the establishment of the Bretton Woods institutions, a great majority of the introduced frameworks have been construed, planned and implemented rather through a perception of a transition 'between known points in time' than along a transformation that results in 'structural change into something yet unknown' (Hettne, 2009, 30). This focus can be mainly attributed to the influential modernisation theories that more broadly entered mainstream policies during the 1940s and 1950s (Martinussen, 1997, 38-39). Presuming '[d] evelopment [...] [to be] the process of transition from one situation to the other', modernisation - through its main motor of economic growth and development-was seen as 'a continuum stretching from poor to rich countries, which would allow for the replication in the poor countries of those conditions characteristic of mature capitalist ones'-such as 'industrialization, urbanization, agricultural modernization, infrastructure, increased provision of social services, and high levels of literacy' (Escobar, $1995,38)$. Thus, the idea of development was clearly linked to a notion of a controllable, progressive transition from one stage to another.

On a more abstract level, the notion of a transition from $\mathrm{A}$ to $\mathrm{B}$ can be directly related to dialectic thinking, where a polar construct sets up a directional path for both problem definition, and problem-solving. As Richard Sennett eloquently summarises this well-established approach, 'in dialectic, as we learned in school, the verbal play of opposites should gradually build up to a synthesis [...]; the aim is to come eventually to a common understanding', and thus reveal 'what might establish that common ground' (Sennett, 2012, 18-19). In other words, dialectic reasoning is driven by an iterative but ultimately linear trajectory that converges oppositional suggestions into a synthesis, compromise or common understanding. Since dialectic problem-solving has been a dominant conceptual framework within Western culture, it has been fairly typical within development discourse to review the status of, and define engagement with low-income environments through opposing constructs as well. It is here where the aspiration to encourage development as a transition from $\mathrm{A}$ to $\mathrm{B}$ usually converges with dialectic reasoning: using real or constructed counterparts has served as the basis for envisioning developmental processes along linear paths. Harold Brookfield (1975), for instance, identifies major dichotomies, such as development and underdevelopment or tradition and modernity, as a crucial part of general development thinking. In his understanding, 'dichotomies, or polarized constructs, are basic to the simplest structuring of human perception into comprehensible order', and '[i]nevitably [...] grow into stereotypes' where '[...] argument often turns to the simpler method - "as if" there were only two classes' (Brookfield, 1975, 53). According to this statement, general thought often remains in simplistic, dual 
categories. Likewise, and particularly focusing on the African context during the early 1980s, geographer Anthony O'Connor detects similar tendencies to use 'crude dichotomies' such as 'developed v. less-developed', 'indigenous v. colonial cities', 'formal v. informal sectors within cities', or 'urban v. rural' when trying to both comprehend African cities and to find solutions to identified challenges (O'Connor, 1983, 21-22). Comparing such statements from the 1970s and 198 os to the contemporary critical accounts of, for instance, Jennifer Robinson, Filip de Boeck, Edgar Pieterse or Garth Myers highlights how persistent the cultural paradigm of polar and dichotomic thinking has been throughout time, disciplines, and geographies (Robinson, 2006; de Boeck and Plissart, 2004; Myers, 2011).

Thus, while dichotomic set-ups and their methodological twin of dialectic thinking might satisfy specific arenas of logical and academic analysis, they are rather prone to providing simplistic approaches when it comes to formulating and implementing policies within the complexities of a specific contexteven more so if the target of analysis involves a foreign environment. While this presumably leads to set-ups that 'crudely impose or emulate an idea or practice promoted as some kind of "universal" solution', it also has an impact on how to engage with the physical environment (Healey, 2010, 6). As Brookfield further states, although many such 'dichotomies [...] are not conceived or elaborated in any spatial context, $[. .$.$] they certainly have spatial implica-$ tions' (Brookfield, 1975, 53). In other words, the abstract nature of dialectic reasoning, dichotomic set-ups and linear transitional thinking very likely leads to a disconnect between analytical thinking and its ramifications for physical environments, and thus ultimately incites a culture of contextual and spatial indifferences.

\section{Contextual and Spatial Indifference}

\section{$\mathbf{2 . 1}$}

\section{Shaping Addis Ababa's Ring Road with Universal Planning and Design Principles}

The following brief portrayal of the Ring Road project in Addis Ababa illustrates how simplistic, linear problem-solving leads to both contextual and spatial indifference, resulting in many challenging outcomes for the city's spatial configuration, on the one hand, and citizens' everyday physical environments, on the other. Involving state-owned Chinese financiers and contractors, local authorities, as well as designs developed by Western engineers, the Ring Road can be seen as an exemplary case study on how economic development and cooperation - within the realm of road infrastructure-is conducted in contemporary Africa (Brautigam, 2009; Foster et al., 2008, 2009). It also serves 
as an illustration of how the neglect of contextual specificities and spatial implications is fostered by aspirations based on supposedly controllable transitional objectives-such as moving from traditional, underdeveloped street conditions to a modern, developed network of urban roads. Whereas the construction of the $33.4 \mathrm{~km}$ long road project started in 1998, was assigned to the China Road and Bridge Corporation (CRBC) and was partially financed by a Chinese loan, the design, planning and tender drawings were executed in collaboration with the British planning consultant Parkman Ltd (Mo et al., 2008) (see Figure 8.1). The circular road consists of both newly built and upgraded road sectors: out of the total length of $33.4 \mathrm{~km}, 19.2 \mathrm{~km}$ were built from scratch, while the remaining $14.2 \mathrm{~km}$ were renewed and adapted according to the new Ring Road layout and standards (Mo et al., 2008). Apart from street

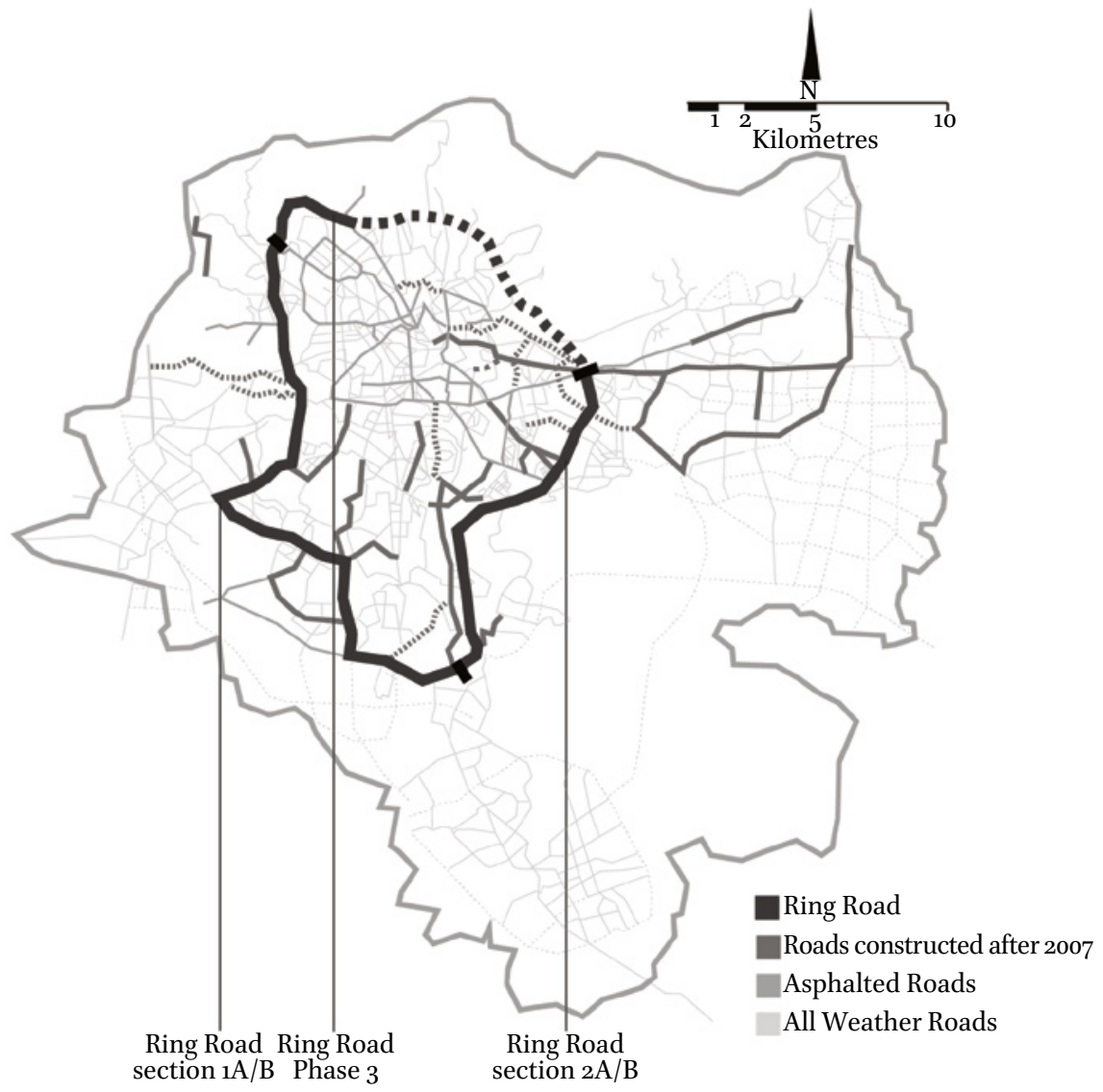

FIGURE 8.1 Ring Road sections and Addis Ababa's road network as of 2010. SOURCE: CONSTRUCTION AHEAD, 2010 (COLOUR ADJUSTMENTS AND ANNOTATIONS BY AUTHOR) 
construction work, the project features an array of supporting structures: six flyovers (bridges), 23 pedestrian bridges and 12 culverts (Mo et al., 2008). ${ }^{2}$

Introducing the first urban highway to Addis Ababa, the adopted approaches to the planning and design of the Ring Road have been strongly influenced by global design norms established and conceived outside of Ethiopia and Africa. Predictably, modern road and highway guidelines have been dominated by American and British standards. While one of the most representative sets of American standards - namely the design policies published by the American Association of State Highway and Transport Officials (AASHTO)-is mainly directed at the context of industrialised countries, the British Transport and Road Laboratory (TRL) has additionally produced a series of so-called Overseas Road Notes (ORNS) specifically aimed at developing countries and mainly focusing on guidelines for interurban and rural roads (TRL [1981] 2003). Accordingly, the Ethiopian Roads Authority's (ERA) guidelines on rural roads primarily use TRL codes, whereas the Addis Ababa City Roads Authority (AACRA) has compiled its Geometric Design Manual mainly along the lines of American and Australian standards (ERA, 2002; AACRA, 2003). AACRA's design manual provides an overall planning and design framework, establishing procedural guidelines regarding urban road categories, road and intersection design, landscaping, pedestrian facilities, safety measures, etc. Unsurprisingly, the combination of AACRA's adoption of American and Australian design standards, the hiring of a British engineering company, and the use of a relatively efficient set-up with Chinese finance and contractors fostered the use of global, ready-made concepts and designs rather than exploring alternative approaches derived from local circumstances, customs and necessities. This approach has been dominated by a fairly technical attitude, where vehicle flows and capacities are at the centre of considerations and the spatial or culturalrelated issues of non-motorised actors are startlingly neglected. In a context such as Addis Ababa, this turns realities upside down: although the majority of traffic participants are pedestrians, road design uses vehicle flows as the main determinant, while pedestrian connections are treated as mere add-on elements. Such a top-down approach to planning inhibits a more systemic perspective that would allow a better understanding of cultural and local specificities: as Tefera Teshome reports in his investigation into the Ring Road, for example, many local citizens would have been willing to contribute their own

2 Due to the currently ongoing construction of the Ring Road's third phase, it is not possible to provide an account of the fully implemented project. Therefore, all quantitative data presented here are related to the completed, first and second stages, which represent approximately 70 per cent of the expected full contour, and were implemented from 1998 to 2004 . 
experiences, resources and even funding - to build bridges, for instance-to the planning process (Teshome, 2011). Ignoring such inputs from local residents, the planning actors involved opted for a rather one-sided typology comprising eight lanes on the same level, four high-speed lanes in the middle and two local feeder lanes on each side, which results in a fairly large and distinct spatial break of approx. 35 metres within the urban fabric (see Figure 8.2). Looking through the propositions of American standards with regard to how to design a street section within urban environments reveals that, indeed, the Ring Road's section design has been directly adapted from a standardised American solution (see Figure 8.3). With no further adaption, this section has been subsequently extended along the whole perimeter of the Ring Road-regardless of the variety of existing spatial conditions (see Figure 8.4).

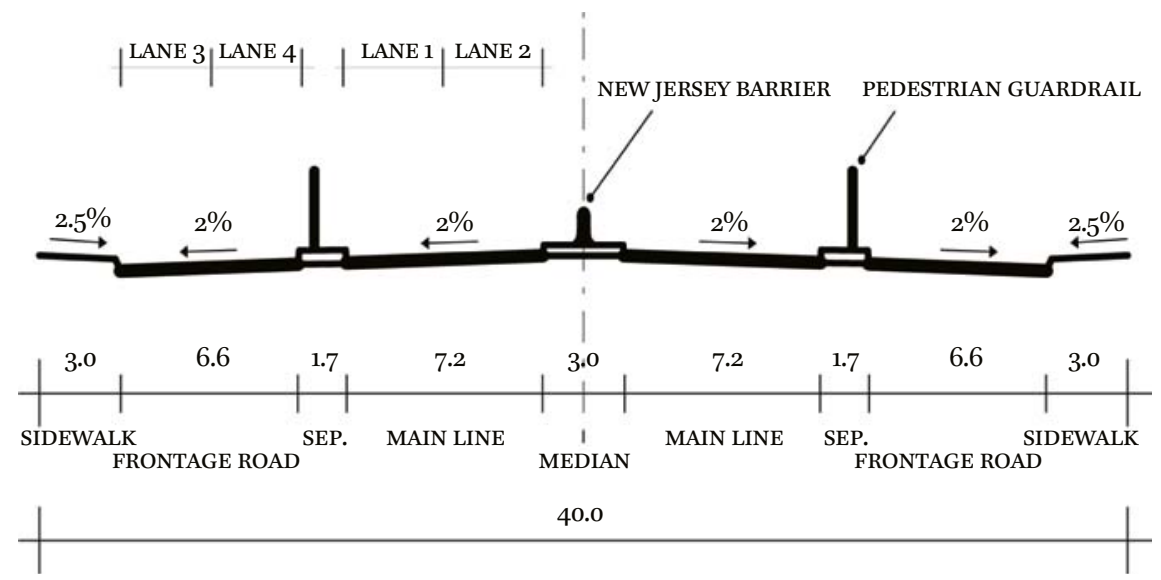

FIGURE 8.2 Schematic diagram of road cross-section geometry. SOURCE: PARKMAN LTD. / ETHIOPIAN ASSOCIATION OF CIVIL ENGINEERS, 1998 (RETRACED BY AUTHOR)

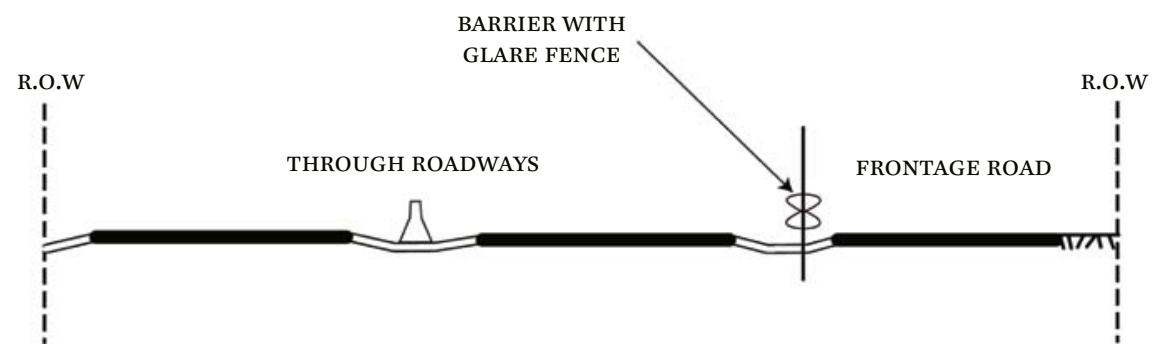

FIGURE 8.3 Restricted cross-section for ground-level freeways. SOURCE: AASHTO, 2004 (RETRACED BY AUTHOR) 


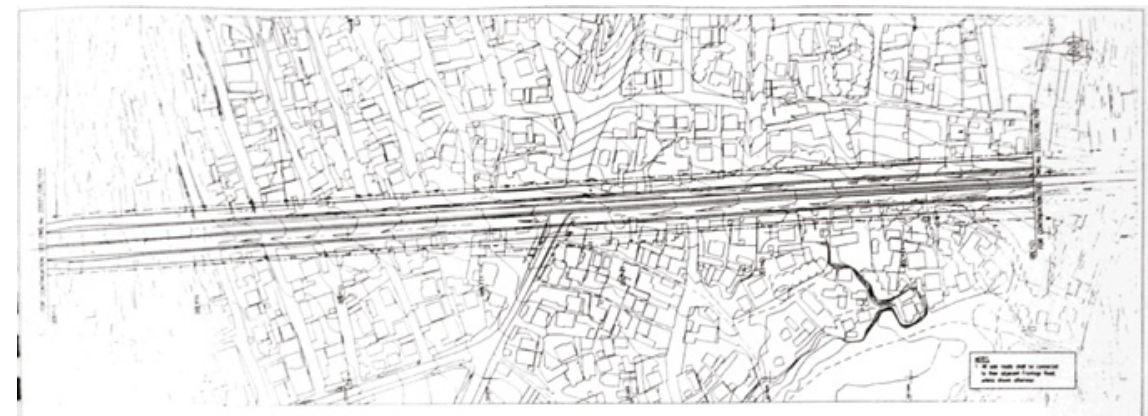

FIGURE 8.4 Ring Road tender drawings, selection of continuous road sections.

SOURCE: FDRE \& PARKMAN, 1997

Using such simplified solutions has certainly been an effective method in the short term: the historically tremendous amount of road constructions (through and beyond the Ring Road) that Addis Ababa has been able to produce within a short amount of time presumably illustrates a potent transition from dusty roads towards an asphalted road network. Yet many of these projects display a clear deficit when it comes to qualitative spatial aspects that go beyond material or technical properties. In the case of the Ring Road, well-established procedural, planning, and design aspects were clearly favoured over a more qualitative, locally driven set of characteristics that could have made it possible to - at least partially — seek a new interpretation of what an urban highway could be in the particular social, economic and spatial context of Addis Ababa.

\subsection{Creating Inadvertent Spatial and Social Side Effects}

Looking at the various spatial and social effects that the design of the Ring Road has caused in Addis Ababa shows how spatially indifferent design features can produce challenging spatial set-ups beyond the abstract technicalities of site allocation, vehicle flows, curvatures and safety measures. The most influential and imminent spatial feature of the Ring Road is its schematic section design. Placing four high-speed lanes in the middle of the road creates a rather rigid spatial barrier not only in the form of the road as such, but also through the applied design itself. The resulting safety measure to place continuous guard rails and concrete partitions along the street and between the road lanes simultaneously produces an impermeable corridor for road users, and, more crucially, a critical obstacle for the pedestrians living in the adjacent neighbourhoods. Losing the different degrees of permeability that normal urban roads, and even arterial urban roads, usually offer, the Ring Road has physically segregated neighbourhoods along its whole perimeter. Closely related to this is pedestrian 
mobility. The planners' approach to pedestrian movement has been rather poor. Addis Ababa's high proportion of pedestrians-half of all trips within the city are made by foot; only 66 vehicles per 1,00o inhabitants-would have justified a more direct integration of pedestrian issues into the centre of design considerations (World Bank and UNECA, 2002, 105). Yet the chosen strategy of installing a series of pedestrian bridges to supposedly fix punctual connection problems reflects a predominantly technical design attitude that considers pedestrians as an abstract number, and not as actors who behave according to their human, economic and social needs. This attitude is clearly exposed through the design and distribution of these pedestrian 'supplements', which are exclusively designed along the functionalistic paradigm of safely and 'rationally' crossing a street from point A to point $B$.

But the Ring Road corridor not only hinders pedestrians' efforts to cross it conveniently, it also complicates vehicle drivers' lateral movements: in order to get across the Ring Road, drivers have to take a 'detour' over the roundabouts and intersections (Bekele, 2012). Furthermore, the installation of a high-speed channel, which is, for most of the time, completely separated from connecting streets, has created challenges that are directly linked to specific local conditions. Coming from a fairly Western understanding of transportation planning, such corridors are usually designed under the assumption of a steady and consistent (high-speed) traffic flow. Even small disruptions of this flow can create substantial traffic jams. Yet in the case of Addis Ababa, such consistency is hardly a given factor. To mention just some examples: the poor material condition of many heavy-load trucks or buses slows them down significantly and often results in the blockage of one lane, or sometimes both lanes (see Figure 8.5); the roundabouts, where all the local modes of transportation come together, create congestion that extends directly into the high-speed corridor; the insufficient maintenance and quality of the Ring Road generate obstacles-such as potholes or pools of water-that considerably slow down the intended consistent flow within the high-speed corridor.

Another crucial spatial effect of the Ring Road's schematic section design is caused by its rigidity. Combined with the overall planning process, the given layout seems to be fairly immune to situational adjustments that go beyond purely technical or functional means. By taking the chosen design as the given solution that accommodates the quite generally calculated capacities, even simple and minor possibilities for adjustments have not been considered. This can be shown, for instance, with the continuous implementation of the same section for the frontage roads. As it turns out, in densely populated more urban areas, these roads are often overcrowded by local vehicles, minibuses, and commercial activities. In contrast, the same layout is outsized in less populated 


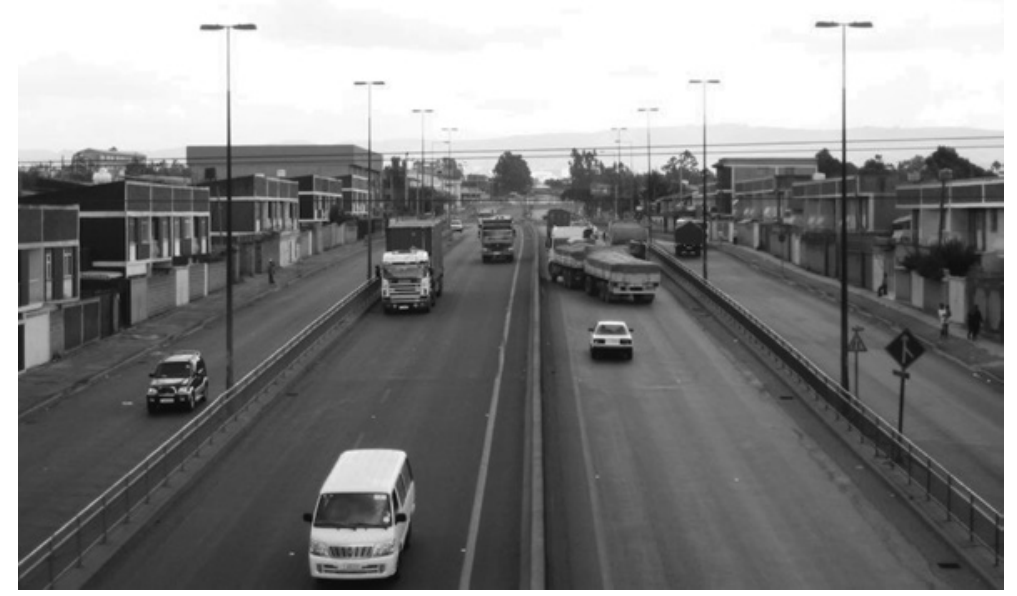

FIgURE 8.5 Traffic jam, Ring Road.

SOURCE: IMAGE BY AUTHOR, 2011

neighbourhoods, where all kinds of different spaces, such as agricultural land or industrial zones, adjoin the Ring Road.

Lastly, there is the issue of physical maintenance, which is related to design decisions for both road layout and materiality. On the one hand, there is the problem of property damage through both accidents and misappropriations. The instalment of relatively valuable elements, such as steel guardrails, incites many citizens to use the Ring Road as a free resource for construction materials (Teshome, 2011). On the other hand, there is a major problem with the Ring Road's drainage system, which has been designed according to British standards, but obviously (and somewhat surprisingly) did not take into account issues of local maintenance capacities, or climatic conditions, resulting in both constantly clogged and undersized drainage pipes. This repeatedly results in flooding (of the Ring Road and other newly built streets) during the rainy season (Bekele, 2012).

On an urban scale, one of the Ring Road's basic justifications was to better regulate traffic and urban growth between the city centre and its peripheries (ORAAMP et al., 2002). Through its circular set-up, the project was supposed to firstly divert through traffic from the city centre and secondly distribute both traffic and urban growth efficiently to the city's peripheries (Mo et al., 2008). Yet, looking at the changes along the project's perimeter, the Ring Road has not only served as this link between centre and periphery, but has itself become 
a zone for urban growth and development. Creating a first, better, or quicker access to different areas of the city, many of the plots adjacent to the Ring Road have experienced extensive spatial transformations. Rather than creating a distinction between a denser city core and dispersed expansion zones, it has accelerated the integration of remaining open territories into an ongoing pattern of suburban development (see Figure 8.6). While the general mechanism of urban development along a new or better route of access is a common result and is practically unavoidable, the specific spatial effects and formations
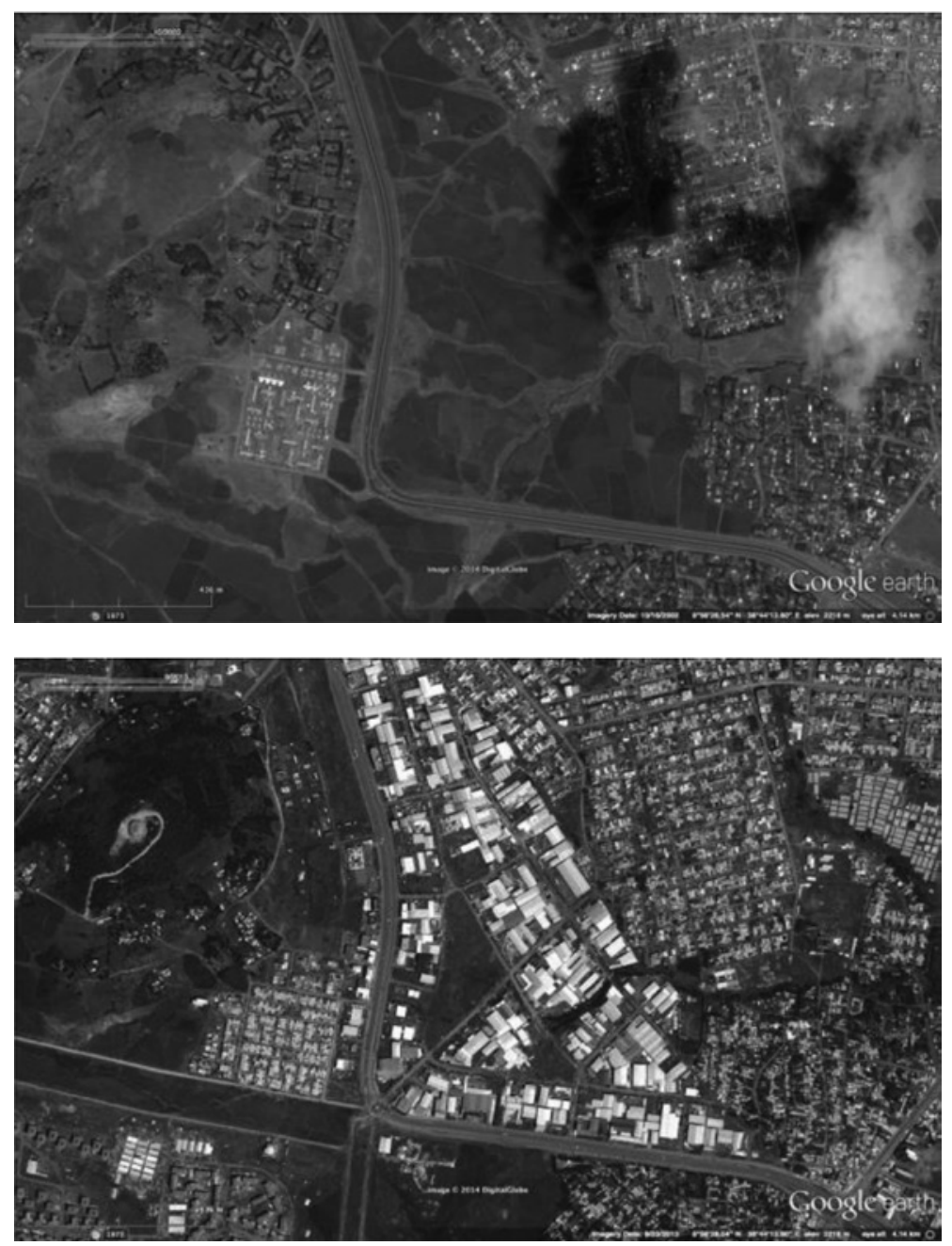

FIGURE 8.6 Industrial and housing development at Quarry Roundabout, 2002 (upper) / 2013 (lower). SOURCE: GOOGLE EARTH/DIGITAL GLOBE, 2014 
on the adjacent territories are often - as illustrated here-not a part of road design and road development. Performing road design from a more holistic perspective than described with the case of the Ring Road would thus implicate that designing a road means simultaneously designing a region, a city and a neighbourhood as well.

As indicated above, the most direct and challenging impacts on citizens' everyday lives caused by the Ring Road are characterised by aggravated crossing conditions. Both the Ring Road layout and the installed overpasses-rigid, ready-made structures replicated along the whole perimeter-can deliberately adapt neither to their immediate spatial surroundings nor to the existing cultural and social customs of Addis Ababa's pedestrian context. Roads as well as the overpasses are often confronted with the realities of street vending, pop-up bus stations, providing shelter, or the presence of animals (see Figure 8.7 and Figure 8.8).

The issue with animals illustrates quite specifically how both planning and design ignore the local context. Donkeys, for example, are still used as an important mode of transportation, especially within the peripheral areas and by people from the lowest income groups. The detours that the Ring Road imposes on these non-motorised participants, directly affects their daily movements, time lines and incomes. Similarly, low-income households that generated a substantial amount of their income through informal petty trade

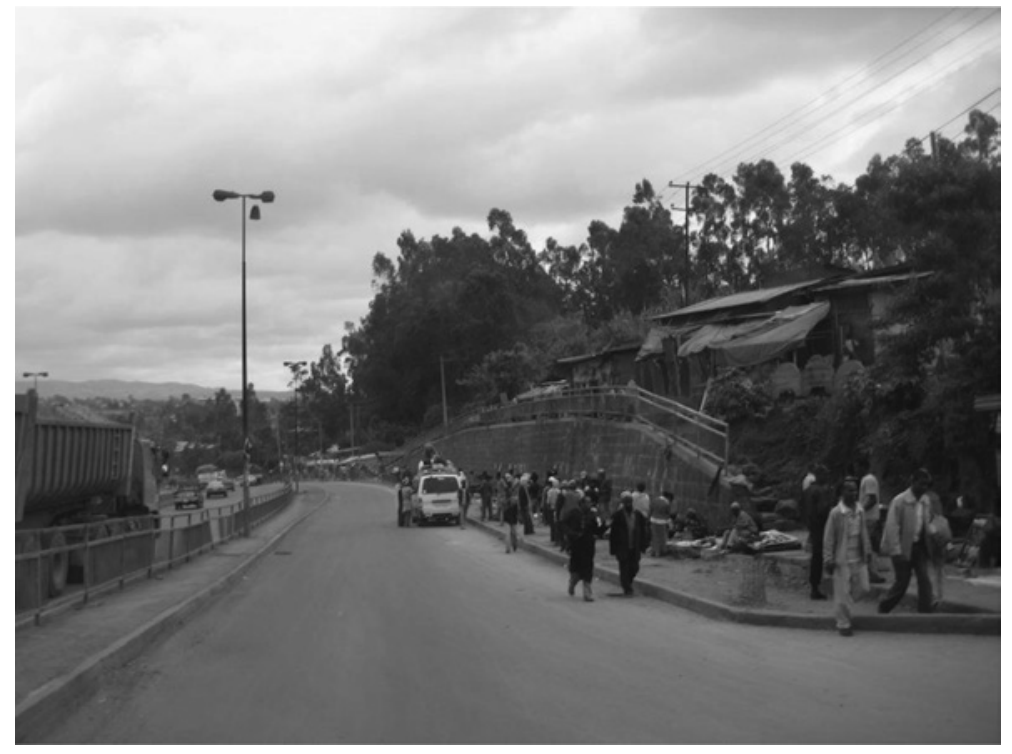

FIGURE 8.7 Street vendors, Ring Road.

SOURCE: IMAGE BY AUTHOR, 2011 


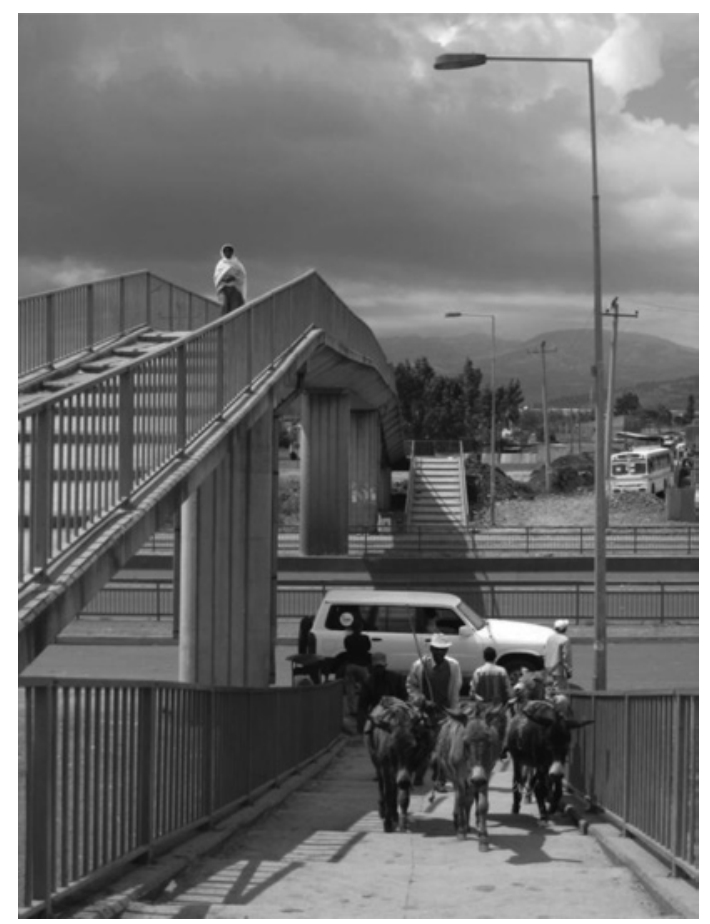

FIGURE 8.8 Animals, Ring Road.

SOURCE: IMAGE BY AUTHOR, 2011

in front of their houses thanks to walk-in customers (selling fire wood or homemade injera bread, for example) have experienced problems due to both relocation and spatial detachment from their immediate business environments (Teshome, 2011). ${ }^{3}$ Apart from these specifically business-related challenges caused by impeded road crossings, different conditions can be identified under which the overpasses perform better or worse for general pedestrians. In more lively and urban surroundings, where the bridges are placed at closer intervals, they can become an almost casual part of the neighbourhoods' daily used infrastructure. Here, the density and mixed activities on both sides of the Ring Road can partially compensate for the otherwise cumbersome crossing of the highway. In areas, however, where adjacent neighbourhoods are defined by mono-functional uses such as housing, industrial production or agriculture, the bridges are usually placed further apart, creating singular bottlenecks for

3 The information compiled regarding such socio-economic issues was gathered in the form of a combination of data gained through personal observation, targeted interviews and studies produced by local researchers—such as Tefera Teshome (2011) or Gebreselassie (2012). 
pedestrian crossings. While this generates an inconvenient detour for children or less agile pedestrians, many pedestrians ignore the overpasses and prefer to jaywalk than to add additional minutes or kilometres to their daily journeys (World Bank and UNECA., 2002) (see Figure 8.9).

Considering the already high number of accidents involving pedestrians in Ethiopia's cities-according to the 2002 Scoping Study on Urban Mobility from the World Bank, Ethiopia has 'one of the highest rates of road accident fatalities' with go per cent of fatalities being pedestrians in cities- the Ring Road's set-up clearly has not contributed to a substantial improvement (World Bank and UNECA, 2002, 40). Again, a sort of disconnection between the contextual realities and the design approach can be observed. Yet, whereas studies - such as the World Bank's - usually reveal that many of these accidents are caused by poorly defined and marked pedestrian facilities, or by pedestrians' erratic movements and behaviour in urban traffic, the proposed improvement measures mainly adhere to common notions of technical problem-solving. Apart from educational measures such as awareness campaigns, the Scoping Study on Urban Mobility, for instance, proposes the construction of additional bridges of a pedestrian-friendly design or even subways, and the installation of 'taller pedestrian barriers [...] to channel pedestrians to these facilities' (World Bank and UNECA, 2002, 41-42). However, given the local social and economic context, it is rather unlikely that the observed challenges can be resolved just by applying more technical and educational procedures-which are, once again, chiefly conveyed by an approach developed for industrialized countries and cities.

A further aspect that links spatial transformations with the socio-economic realm is signified by resettlements. In the course of implementing the Ring Road, the city government had to relocate and compensate dwellers affected by the increased spatial needs of the respective designs. Some sources, such as Mo et. al., state that 'local people forwardly assisted [the authorities] and were satisfied with the compensation for resettlements'(Mo et al., 2008, 7), while other sources report repeated challenges during these processes. According to Teshome's investigations, for instance, house owners complained that compensation for their demolished houses was too low because the applied formulaic calculations did not take replacement costs into account (Teshome, 2011). In the case of demolished Kebele housing units- the stateowned, low-end housing stock - tenants were paid Етв 1,200 (USD 146) in cash, which was supposed to cover relocation to other rental units and additional rent costs for 12 months (Gebreselassie, 2012). Within and after these 12 months, the government promised to provide alternative Kebele housing units. In view of the general housing shortage however, many inhabitants refused to take cash compensation, and demanded alternative housing units right 


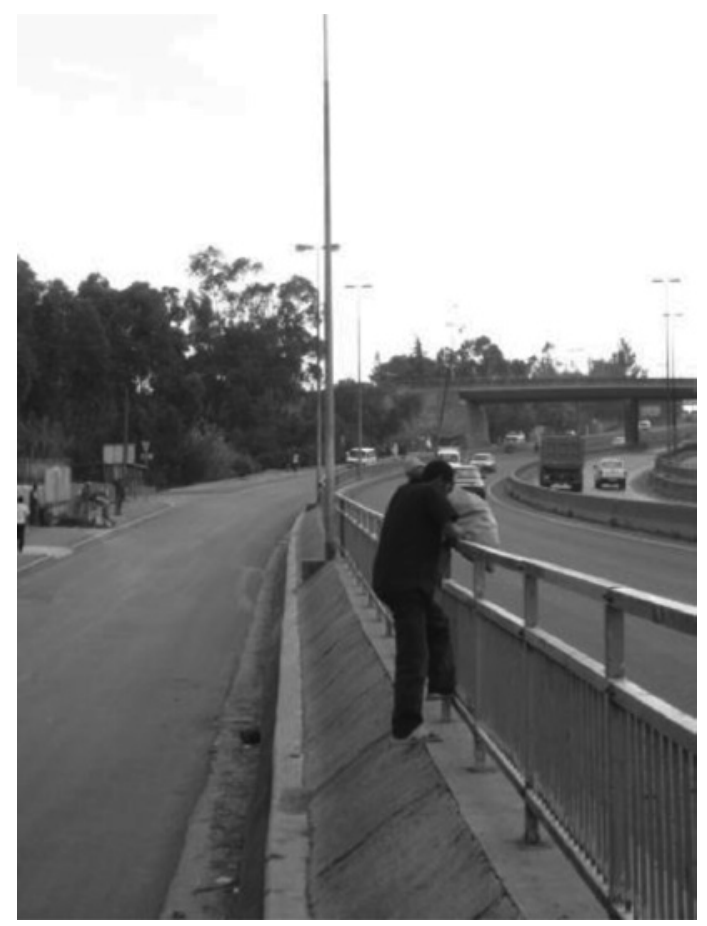

FIGURE 8.9 Jaywalking, Ring Road.

SOURCE: IMAGE BY AUTHOR, 2011

at the outset. The administration eventually reacted by providing low-cost housing units on the periphery of the city, often incurring higher transportation costs for residents and disconnecting the affected citizens from their communities within established neighbourhoods. ${ }^{4}$

\section{$3 \quad$ Alternative Views on Urbanisation and Spatial Formation}

\subsection{Addressing Urbanisation Through a More Ordinary and Less Ideological Mindset}

The approaches and results briefly illustrated by the examination of the Ring Road project show how rather simplistic and technocratic understandings of

4 Connected with the resettlements caused by the Ring Road, Teshome (2011) further describes an important socio-economic issue that is omnipresent in any kind of relocation of Ethiopian low-income groups: the dismantling of the so-called iqqubs and iddirs. Iddirs are burial associations and iqqubs informal savings associations, and both are strongly embedded within the social structure and spatial proximity of neighbourhoods. 
urbanisation foster contextual and spatial indifference through universally applied models. This, and a de facto ignorance of the impact of such interventions on spatial formation, clearly begs a critical rethink of the underlying theoretical and practical concepts - both regarding the exploration of urban processes and the development of a spatially conscious attitude.

With regard to reframing existing concepts of urbanisation and urban processes as such, there is a series of critical, contemporary accounts that suggest a more reality-based, multifaceted, contextual attitude towards research and practice. Two important perspectives within this body of research and literature are briefly addressed here. Jennifer Robinson's book Ordinary CitiesBetween Modernity and Development (2006) is a foundational example of this position on a global scale. Based on a postcolonial critique that during the past century dominant strands of urban research and practice were directly influenced by the overall discourse on modernisation and 'under-development', Robinson suggests an alternative vantage point when addressing cities all over the globe. Instead of ideologically labelling cities as modern and traditional, or developed and underdeveloped counterparts, Robinson demands 'that theorising about cities should be more cosmopolitan, should be resourced by a greater diversity of urban experiences', suggesting that this could ultimately lead to an understanding of every city as an ordinary entity in its own right (Robinson, 2006, 6). She further argues that this would require 'an urban theory substantially committed to comparative work', which is generally 'suspicious and cautious about deploying categories and hierarchies and eager to promote strategies for city improvements that build on their distinctive and individual creativities and resources' (Robinson, 2006, 6).

Mainly focusing on the African context, the work of urban scholar Edgar Pieterse argues along similar lines. According to Pieterse, a thorough and adequate understanding of particular urban realities and processes demands a broader base of fundamental knowledge and research: unfolding a multifaceted pool of knowledge, cultural mindsets, ideas, concepts and disciplines would ultimately lead to a deeper and more genuine understanding of what constitutes African cityness (Pieterse, 2010). To achieve this, he suggests that we 'cross-fertilise ethnographic texture, sociological patterning and topographies, spatial practices and registers and interpretive metaphors that stem from speculative philosophical enquiry and literary theory in the broad sense of the term' (Pieterse, 2010, 217). According to Pieterse, this approach would not only foster necessary, more contextual and comprehensive knowledge on African cities, it would also offer a path 'towards a more dispassionate approach' that could level out many of the extreme 'a priori moral assumptions about what 
is good, moral and modern, and what is not, and therefore unworthy of study, or if studied, not to be valorised' (Pieterse, 2013, 28). A dispassionate approach would therefore invest more energy in exploring 'the real city, the real economy and the real social practices and identities of the majority of urbanites who are building our cities' (Pieterse, 2013, 28). Pieterse (2013) further indicates the kind of strategy needed to perform such a research approach: converging multiple fields of expertise, such as quantitative and statistical data, literary descriptions of the urban experience, or relevant philosophical frameworks into one narrative could generate a multifaceted, reflective and critical proposition that would engage with the given urban realities, and thus would clearly move beyond contextual indifference.

\subsection{Acknowledging the Importance of Spatial Production and Spatial Agency}

While the deliberations of Robinson and Pieterse represent seminal contributions to starting re-conceptualising the study of urban issues on a methodological and theoretical level, a comprehensive inclusion of what the role - and potential — of physical space might be is still rather restrained. Yet, intrinsically linked to spatial outcomes, an exploration of new conceptions of urbanisation and urban development would have to be accompanied by investigating new notions of what the role of physical space and the built environment might be. Usually within an environment of spatial indifference, spatial formations of territory and the built environment are serving as abstract vessels that physically absorb economic progress. Territory and built structures therefore mainly represent the general, yet essential, substrate that serves to process the desired development-without consciously including the unconditional social practices that are part of everyday spatial production. Keller Easterling, for instance, convincingly describes the results of such overall processes deriving from global networks of exchange and production as spatial products that are procedural by-products of financial flows and their underlying organisational patterns rather than deliberately planned physical environments (Easterling, 2005). Under such premises, the physical environment's function is based on a sort of spatial servitude, where space, territory and the built structures are mainly conceived as the necessary material translators of political and economic activities.

Seeking to depart from such a one-sided understanding of the physical realm, the theoretical work of sociologists Henri Lefebvre and Bruno Latour offer instrumental insights and potentials. When it comes to addressing the production of social and physical urban spaces, Henri Lefebvre's writing on 
cities has become a well-known and widely discussed reference. This has to do not only with his framework's ability to adapt to different forms of social and political economies over time, but also with his model's set-up as a more comprehensive, interrelated model of analysis that includes political, economic, social and spatial aspects of urban formation. The analytical tool provided by Lefebvre's conceptual triad of spatial practice, representation of space, and representational space becomes particularly important within an environment of spatial indifference, since it forces one to think of spatial production as an interrelated process comprising various actors, sectors and disciplines. Lefebvre himself identifies the category representation of space-which reflects 'conceptualized space, the space of scientists, planners, urbanists, technocratic subdividers and social engineers' - as the usual 'dominant space in any society (or mode of production)' (Lefebvre, [1974] 1991, 38-39). Following Lefebvre's analysis, this dominance is the outcome of a particular political economy where 'the state and its bureaucratic and political apparatuses intervene continually in space, and make use of space in its instrumental aspect in order to intervene at all levels and through every agency of the economic realm' (Lefebvre, [1974] 1991, 378). Yet, while the analytical combinations enabled by Lefebvre's model allow us to engage with spatial production more comprehensively, it can be argued that the conceptual triad is still grounded on a certain assumption of physical spatial subordination: although social, political and cultural spaces constantly produce, reproduce and appropriate the built environment, the role of physical space is still a proxy for the portrayed mechanisms rather than a deliberately recognised, active player that is not only filled, generated and adopted, but also initiates change and actions on its own terms. Thus, when recapitulating Lefebvre's statement that space is instrumentally used - and therefore subordinated — to 'intervene at all levels' and 'through every agency of the economic realm', one would have to attribute agency to the various aspects of physical space as well (Lefebvre, [1974] 1991, 378). In other words: pursuing the idea that the physical environment can be a decisive actor on its own terms within a social environment would require introducing a concept of spatial agency.

One of the most substantial impulses that non-human objects-for example, the built environment - can participate in as actors within the social sphere derives from the so-called actor-network theory (ANT) as most prominently formulated by Bruno Latour. Latour qualifies non-human elements as determining components of society, which, indeed, can feature inherent agency as well. Given the fact that for most social models agency is directly linked to intentionality, reflexivity or meanings—a condition only humans 
can fulfil-Latour proposes a more abstract notion of agency that is based on the pure ability to change things as such. From this perspective, 'any thing that does modify a state of affairs by making a difference is an actor' and therefore 'the questions to ask about any agent are simply the following: Does it make a difference in the course of some other agent's action or not?' (Latour, 2005, 71). Apart from these rather general considerations, Bruno Latour and Albena Yaneva give a brief glimpse of how the ANT's perspective could be applied to architecture-and thus to the general built environment as well. Criticising traditional architectural theory's distant way of discussing buildings as more or less neutral objects of the non-human sphere, the authors claim that-in reality-'everyone knows that a building is a contested territory and that it cannot be [only] reduced to what is and what it means' (Latour and Yavena, 2008, 86). Rather, from their perspective, a built structure should be understood in 'the way it resists attempts at transformation, allows certain visitors' actions and impedes others, bugs observers, challenges city authorities, and mobilises different communities of actors' (Latour and Yavena, 2008, 86). In this sense, a particular typology can not only be seen as the physical product of respective practices: the mere availability of a typology basically makes it an actor on its own behalf and creates a situation where a clear line between supply and demand no longer exists. Thus, if a certain typology did not exist, it would be impossible to establish this specific high-speed urban road network in such a short amount of time-or it would not even be considered in the first place. Although partially altered and adapted, the archetypes, technologies and design processes available within the global toolbox of universal solutions can be seen as active contributors to decision-making. Looking at the explored physical results and social effects of a system conceived by spatial servitude, it is, in fact, exactly along categories mentioned by Latour and Yavena $(2008,86)$ where the built environment could become an agent for other conceptions and attitudes: with the ability to 'resist attempts of transformation', 'challenge city authorities', or 'mobilize communities', for example, built structures and spatial formations could be more deliberately designed and organised to actively and adequately engage with respective everyday spaces, rather than being a sole accomplice of translating economic processes into space. Whether this approach would better deal with critical side effects fostered by economic agency is not entirely clear. What appears obvious though is that a more conscious attitude towards spatial agency could have the potential of introducing a crucial dimension of spatial real-life issues within economic development, development cooperation, urban planning and particular design practices. 


\subsection{Moving Away from Linear Spatial Problem-Solving Towards More Adequate Spatial Practices}

Driven by the similar aim to dissolve the rigid structure of dialectic discourse and thinking in opposites, Richard Sennett considers an alternative and more open framework for discourse. By referring to the Russian literary critic Mikhail Bakhtin, who conceived the expression dialogic discussion, Sennett reflects on this notion 'to name a discussion which does not resolve itself by finding common ground': although, in consequence, 'no shared agreements may be reached, through the process of exchange people may become more aware of their [...] views and expand their understanding of one another' (Sennett, 2012, 19). The deliberate set-up of a dialogic discussion, where a synthetic solution 'by a play of contraries leading to agreement' is not the final objective, would allow 'bouncing off views and experiences in an open-ended way' (Sennett, 2012, 24). What if Sennett's differentiation of dialectic argument and dialogic discussion was extended to spatial planning, and design processes? A dialogic design and planning approach, as it were, that would automatically contest the notion of seeking transitions from A to B, or ideal, universal, and common solutions at all costs. Dialogic planning would encourage simultaneously testing different prototypes, proposals and models. In doing so, it would more adequately address the multitude of given real-life issues by contributing - in the words of Patsy Healey— to a "pool" of knowledge' that fosters an open, diverse collection of actors, ideas and approaches within the realm of physical spatial production (Healey, 2010, 6). But a truly dialogic set-up would not only encourage a larger variety of possible ideas and solutions; it would crucially alter the way that actors from different cultural, economic, disciplinary and geographic backgrounds could cooperate with one another. Dialogic design and planning would ultimately mean that all respective stakeholders-neighbourhood representatives, local and foreign experts, local authorities, designers and NGOswould have an equally important seat at the table from which to bring forward respective knowledge, concerns and proposals regarding how to conceive, design, implement and maintain the built environment. It would also mean that such a group would not have to agree on one or two common, overall solutions, but could negotiate, for example, a set of different approaches that were tailored for different social, economic and spatial circumstances. And finally, dialogic design and planning would inherently include the notion of spatial agency, since the produced proposals and prototypes embedded within particular built environments would induce a direct discourse on spatial impacts, challenges and performance as well. 


\subsection{Using the Power of Collective Knowledge}

Although the propositions and deliberations put forward in the previous paragraph might seem diverse, they nevertheless share some mutual criteria that could, when associated with each other, offer a powerful integrative and comprehensive approach for spatial practices. Departing from abstract dialectic and transitional problem-solving, they all offer a) ways towards less universal but more reality-based solutions; b) more inclusive, open-ended planning and design processes; and c) a more comprehensive and interrelated understanding of policy and space. In contrast to an exclusive and conventional top-down arrangements of experts, models or methodologies, this approach would consist of a collective body of knowledge, evolving from a bottom-up attitude and feeding its power from truly transdisciplinary (including local residents, neighbourhood associations, industry experts, academics, public administrative staff, politicians, activists, etc.) and interdisciplinary (including actors from the fields of design, urban design, urban planning, anthropology, sociology, economics, engineering, cultural studies, etc.) set-ups.

In reference to the common ground sought by a dialectic argument, a dialogic discussion could thus aim towards a collective ground, where both a collection of ideas and a collective constellation of actors would aim at resolving complex urban issues with a heterogeneous, open, extendable and flexible set of different concepts, ideas and approaches. Dialogic modes of thought and exchange could eventually move away from oppositional set-ups that drive transitions towards precast solutions, and instead promote a plurality of ideas and techniques. Intentionally configured as a productive 'site of struggle' (as suggested by Patsy Healey) an approach based on a dialogic discussion would further incorporate actors and aspects that are often excluded from such processes - such as small-scale personal initiatives, cooperatively organised networks and locally-driven practices - and thus be more receptive to alternative takes, and more resilient towards unforeseen changes (Healey 2010, 6).

Based on the above-mentioned propositions, the idea of a collective ground would act as a relational network of concepts that comprises a) an ordinary and dispassionate attitude towards urban studies; b) comprehensive spatial analyses and the awareness of spatial agency; and c) an open-ended dialogic approach towards problem definition and solution finding. With regard to the presented case of urban road construction, for instance, such an approach would start the planning and design process with some essential questions to be answered by all involved stakeholders (local citizens, local and international experts from various disciplines, governmental representatives, NGOs), 
spurring participatory practice on a conceptional level: does Addis Ababa need an urban highway at all? If so, what is an urban highway in the context of Addis Ababa? How can a road adequately address the needs of the city's pedestrian majority? How can a road address the spatial, social and economic realities on the ground? Can a road design do more than solely accommodate calculated traffic flows? And what are the aspired spatial and economic impacts on both the affected neighbourhoods and the city as a whole?

Ultimately, allowing a flatter hierarchy and a more basic array of questions, ideas, concepts and possibilities, seeking collective ground could not only-as Garth Myers imagines-'point to the multifaceted urbanity in African contexts as a great value to global understanding of urbanism', it could also begin to dissolve the notions of opposite, transitional set-ups for urbanisation, design practices, urban planning, and economic policies as mainly defined by Western standards (Myers, 2011, 7). From this perspective, structural change into something yet unknown would literally mean opening up the way for a multitude of contextual, inclusive and innovative spatial practices that could not have been solely imagined at the desks and in the minds of established experts, administrations or remote foreign actors.

\section{Acknowledgements}

This chapter is based on the author's dissertation, which was supported by the Department of Architecture of ETH Zurich, the Future Cities Laboratory in Singapore, and the Swiss National Science Foundation (SNSF). The author would like to thank all involved reviewers for their critical and helpful input.

\section{References}

AACRA (Addis Ababa City Roads Authority) (2003) AACRA Geometric Design Manual. (Addis Ababa: AACRA).

Bekele, S. (2012) 'New Roads, Old Problems', Capital, http://capitalethiopia.com /2012/08/06/new-roads-old-problems (accessed on 1 November 2013).

Brautigam, D. (2009) The Dragon's Gift-The Real Story of China in Africa (Oxford: Oxford University Press).

Brookfield, H. (1975) Interdependent Development (London: Methuen \& Co). de Boeck, F. and M.-F. Plissart (2004) Kinshasa-Tales of the Invisible City (Ghent: Ludion). 
Duminy, J., N. Odendaal and V. Watson (2014) 'The Education and Research Imperatives of Urban Planning Professionals in Africa' in S. Parnell and E. Pieterse (eds.) Africa's Urban Revolution (London and New York: Zed Books), pp. 184-199.

Easterling, K. (2005) Enduring Innocence-Global Architecture and its Political Masquerades (Cambridge, MA: The MIT Press).

Escobar, A. (1995) Encountering Development: The Making and Unmaking of the Third World (Princeton: Princeton University Press).

ERA (Ethiopian Roads Authority) (2002) Geometric Design Manual 2002 (Addis Ababa: Ethiopian Roads Authority).

Flyvbjerg, B. (2004) 'Phronetic Planning Research: Theoretical and Methodological Reflections', Planning Theory \& Practice, 5(3), pp. 263-306, DOI: 10.1080 /1464935042000250195.

Foster, V., W. Butterfield, C. Chen and N. Pushak (2009) Building Bridges-China's Growing Role as Infrastructure Financier for Sub-Saharan Africa (Washington D.C.: World Bank).

Foster, V., W. Butterfield, C. Chen and N. Pushak (2008) 'China's Emerging Role in Africa-Part of the Changing Landscape of Infrastructure Finance', Gridlines, No. 42 (Washington D.C.: World Bank).

Gebreselassie, E. (2012) 'Addis Ababa Administration Has a Lot to Do to Make Addis Habitable', Capital (Online) (accessed on 1 November 2013).

Healey, P. (2010) 'The Transnational Flow of Knowledge and Expertise in the Planning Field', in P. Healey and R. Upton (eds.) Crossing Borders-International Exchange and Planning Practices (Oxon and New York: Routledge), pp. 1-25.

Hettne, B. (2009) Thinking about Development (London and New York: Zed Books).

Latour, B. (2005) Reassembling the Social-An Introduction to Actor-Network-Theory (New York: Oxford University Press).

Latour, B. and A. Yavena (2008) 'Give Me a Gun And I Will Make All Buildings MoveAn ANT's View of Architecture', in R. Geiser (ed.) Explorations in ArchitectureTeaching, Design, Research (Basel and Boston: Birkhäuser), pp. 80-89.

Lefebvre, H. ([1974] 1991) The Production of Space (Oxford and Cambridge: Blackwell). Low, S.M. (2014) 'Spatialities: The Rebirth of Urban Anthropology through Studies of Urban Space', in D.M. Nonini (ed.) A Companion to Urban Anthropology (New York: John Wiley \& Sons), pp. 15-27.

Martinussen, J. (1997) Society, State and Market-A Guide to Competing Theories of Development (London and New Jersey: Zed Books).

Mo, P., R.J. Orr and J. Lu (2008) Addis Ababa Ring Road Project-A Case Study of a Chinese Construction Project in Ethiopia, paper presented at the International Conference on Multi-national Construction Projects: Securing High Performance through Cultural Awareness and Dispute Avoidance, Shanghai, 21-23 November. 
Myers, G.A. (2011) African Cities-Alternative Visions of Urban Theory and Practice (London and New York: Zed Books).

O'Connor, A. (1983) The African City (London: Hutchinson \& Co. Publishers).

Okpala, D.C. (1990) 'The Roles and Influences of External Assistance in the Planning, Development and Management of African Human Settlement Systems', Third World Planning Review, 12(3), pp. 205-229, DOI: 10.3828/twpr.12.3.m26531624816127. ORAAMP (Office for the Revision of the Addis Ababa Master Plan), Addis Ababa City Government and Works and Urban Development Bureau (2002) City Development Plan 2001-2010-Executive Summary (Addis Ababa: ORAAMP).

Pieterse, E. (2013) 'Grasping the Unknowable: Coming to Grips with African Urbanisms', in E. Pieterse and A. Simone (eds.) Rogue Urbanisms-Emergent African Cities (Johannesburg: Jacana Media), pp. 19-37.

Pieterse, E. (2010) 'Cityness and African Urban Development', Urban Forum, 21(3), pp. 205-219, DOI: 10.1007/s12132-010-9092-7.

Robinson, J. (2006) Ordinary Cities-Between Modernity and Development (Oxon and New York: Routledge).

Sennett, R. (2012) Together-The Rituals, Pleasures and Politics of Cooperation (London: Allen Lane / Penguin Group).

Teshome, D. (2011) The Effects of Urban Development in Addis Ababa-A Study of the Belt Highway Project (Saarbrücken: VDM Verlag Dr. Müller).

TRL (Transportation Research Laboratory) ([1981] 2003) Overseas Road Note 1Maintenance Management for Regional and District Engineers (Crowthorne: TRL Limited).

Ward, S.V. (2010) 'Transnational Planners in a Postcolonial World', in P. Healey and R. Upton (eds.) Crossing Borders-International Exchange and Planning Practices (Oxon \& New York: Routledge), pp. 47-72.

World Bank and UNECA (United Nations Economic Commission for Africa) (2002) Scoping Study: Urban Mobility in Three Cities. Addis Ababa, Dar Es Salam, Nairobi, SSATP Working Paper No. 70 (Washington D.C.: World Bank).

Yin, R.K. (2003) Case Study Research-Design and Methods (London and New Dehli: Sage Publications). 